\title{
A INFLUÊNCIA DO BANCO MUNDIAL NA EDUCAÇÃO BRASILEIRA: A DEFINIÇÃO DE UM AJUSTE INJUSTO
}

\author{
LA INFLUENCIA DEL BANCO MUNDIAL EN LA EDUCACIÓN BRASILEÑA: LA \\ DEFINICIÓN DE UN AJUSTE INJUSTO
}

\section{THE INFLUENCE OF THE WORLD BANK ON BRAZILIAN EDUCATION: THE DEFINITION OF AN UNFAIR ADJUSTMENT}

\author{
DOI: http://dx.doi.org/10.9771/gmed.v1111.31889
}

Franciel Coelho Luz de Amorim ${ }^{1}$

Maria Jorge dos Santos Leite ${ }^{2}$

\begin{abstract}
Resumo: O artigo analisa as definições e orientações do Banco Mundial nas políticas educacionais brasileiras e identifica as novas orientações propostas por esse organismo a partir da imposição de um ajuste considerado "justo" pelo Banco Mundial à educação brasileira. Para tanto, balizamos a revisão de literatura nas evidências de atuação do órgão com as políticas de educação nacionais, dando suporte a análise de dois documentos: "Atingindo uma educação de nível mundial no Brasil: Próximos Passos" e em "Um Ajuste Justo - Análise da Eficiência e Equidade do Gasto Público no Brasil", no qual o Banco traça, na última parte, as linhas gerais das principais reformas de educação que o país necessita adotar para seguir seu papel periférico na esteira do neoliberalismo, enxugando os gastos do Estado, mediante reformas que abrem caminho à privatização da educação pública.
\end{abstract}

Palavras-chave: Banco Mundial; Políticas Educacionais; Privatização; Brasil.

Resumen: Lo articulo analiza las definiciones y orientaciones del Banco Mundial en las políticas educacionales brasileñas e identifica las nuevas orientaciones propuestas por ese organismo a partir de la imposición de un ajuste considerado "justo" por el Banco Mundial a la educación brasileña. Para tanto, balizamos la revisión de literatura en las evidencias de actuación del órgano con las políticas de educación nacionales, dando suporte la análisis de dos documentos: "Alcanzando una educación de nivel mundial en lo Brasil: Próximos Pasos" e en "Un Ajuste Justo Análisis da Eficiencia e Equidad do Gasto Público en lo Brasil”, no cual lo Banco traza, en la última parte, las líneas generales de las principales reformas de educación que lo país necesita adoptar para seguir su papel periférico en la estera del neoliberalismo, secando los gastos del Estado, mediante reformas que abren camino a la privatización de la educación pública.

Palabras-clave: Banco Mundial; Políticas educacionales; Privatización; Brasil.

Abstract: The paper analyzes the definitions and orientations of the World Bank in the brazilian educational policies and identifies the new orientations proposed by this organization through imposition of an adjustment considered "fair" by the World Bank for education in Brazil. Therefore, it was beaconed in a literature review, the evidence of agency by the organization on the national educational policies, beaconing that backed up the analysis of two documents: "Achieving a world class education in Brazil: next steps" and "A fair adjustment - Analysis of efficiency and equity of Public spending in Brazil", in which the bank draws, in general outlines, the main educational reforms the country needs to adopt to perform its peripheral role in the wake of neoliberalism, drying out State expenses through reforms that open path to the privatization of public education.

Keywords: World Bank; Educational policies; Privatization; Brazil. 


\section{Introdução}

Este artigo possui por objetivos identificar as definições e orientações do Banco Mundial às políticas educacionais brasileiras, bem como analisar a avaliação realizada pelo organismo sobre as implicações das políticas educacionais implementadas pelo Estado brasileiro nas últimas duas décadas, assim como de identificar as novas orientações propostas a partir da imposição de um ajuste considerado "justo", pelo Banco Mundial, à educação brasileira.

Para cumprir estes objetivos, adotamos os seguintes procedimentos metodológicos: revisão de literatura sobre a influência do Banco Mundial nas políticas educacionais do Estado brasileiro. Isso porque, diversos estudos recentes (MAUÉS e MOTA JÚNIOR, 2014; PEREIRA, 2014; PRONKO, 2014; SOUZA, 2014; VIOR e CERRUTI, 2014;) comprovam que, a partir da década de 1990, foi crescente a influência deste organismo nas orientações e definições das políticas educacionais, as quais foram prontamente aceitas e executadas pelos últimos governos brasileiros.

Marilsa Miranda Souza (2014), ao realizar uma leitura atenta à legislação brasileira desenvolveu a compreensão de que:

O banco intervém na educação brasileira por meio da imposição de políticas educacionais e de empréstimos a programas e projetos educativos que fazem parte da reforma estrutural do capitalismo. Essas políticas se expressam claramente por meio da legislação brasileira. Por meio da legislação, se orienta todos os setores da educação e seus objetivos (SOUZA, 2014, p. 127).

De tal maneira, realizamos uma análise, não diretamente na legislação, mas nos dispositivos que a orientam e impõem modificações: duas publicações do Banco Mundial sobre a educação no Brasil. Primeiro, foi o documento "Atingindo uma educaşão de nivel mundial no Brasil: Próximos Passos", publicado em 2010 pelo BM, o qual possui como objetivo principal a realização de um balanço das reformas educacionais, definidas e orientadas pelo órgão, na educação brasileira no período que compreende 1995 a 2010, respectivamente os dois mandatos tanto de Fernando Henrique Cardoso (FHC) quanto de Luís Inácio Lula da Silva, bem como de seguir orientando os rumos das políticas educacionais no país.

Em seguida, abordamos, em parte, a recente publicação do Banco Mundial intitulada de "Um Ajuste Justo - Análise da Eficiência e Equidade do Gasto Público no Brasil", enfocando o último tópico do documento que aborda os gastos em educação e recomenda um ajuste de gastos na educação considerado “justo", aos olhos do organismo.

O trabalho está organizado em dois tópicos: o primeiro está circunscrito à revisão da literatura acerca da influência do Banco Mundial nas políticas educacionais brasileiras; já o segundo se organiza em torno dos dois documentos do Banco Mundial analisados neste trabalho: um na avaliação que o Banco fez nas políticas neoliberais de educação implantadas nos governos de FHC e de LULA; e outro, como contribuição maior deste trabalho, em análise nas mais recentes definições e orientações do referido organismo para às políticas de educação no Brasil. $\mathrm{O}$ texto analisado, parte de um estudo maior, é intitulado "Gastar Mais ou Melhor? Eficiência e Equidade da Educação Pública", no qual o Banco Mundial define as suas novas medidas e reformas neoliberais à sociedade brasileira, cabendo ao governo implementá-las. 


\section{A influência do Banco Mundial nas políticas educacionais brasileiras}

Há décadas organismos internacionais, a exemplo do Banco Mundial, têm atuado na prática de empréstimos aos países periféricos da América Latina, exercendo sobre estes, controle econômico, cultural, político e educacional. No Brasil, as políticas educacionais estão atravessadas por relações com esses organismos, cujos objetivos é reverter a crise do sistema capitalista desencadeada na década de 1970, por meio da mercantilização do ensino.

A crescente intervenção dos organismos internacionais na definição de políticas públicas na América Latina, a partir de meados do século XX, torna impossível compreender totalmente os processos nacionais sem considerar as concepções, os diagnósticos e as propostas por eles produzidos e difundidos. Essa afirmação não implica desconhecer os níveis de autonomia e de responsabilidade dos Estados nacionais na aceitação dessas orientações e suas traduções em razão da história de cada país. (VIOR; CERRUTI, 2014, p.113).

A assertiva acima, retirada do texto "O Banco Mundial e a sua influência na definição de políticas educacionais na América Latina (1980-2012)", de Susana Vior e María Betania Oreja Cerruti, define bem a relação que objetivamos explorar neste trabalho, especificamente no papel do Banco Mundial como definidor das políticas de educação aplicadas pelo Estado brasileiro, a partir da década de 1990. No entanto, assevere-se de que a influência deste organismo internacional, assim como de vários outros, se faz presente de muito antes, porém com direta intervenção à educação somente a partir dos anos de 1990.

$\mathrm{Na}$ América Latina e no Brasil, em especial, ocorreu com o término da Segunda Guerra Mundial (1939-1945) o predomínio da interferência dos Estados Unidos - EUA, fazendo esse continente refém da hegemonia externa exercida pelos norte-americanos, especialmente no campo tanto da economia quanto da política $^{3}$. Essa hegemonia se fortalecerá e se ampliará ao longo do tempo, sobretudo, pela criação e atuação de agências e órgãos controlados pelo capital financeiro internacional, como o Fundo Monetário Internacional - FMI, Banco Mundial - BIRD, Organização Mundial do Comércio - OMC, Organização das nações Unidas - ONU, Organização do Tratado do Atlântico Norte - OTAN, etc.

De tais organismos, se destaca o chamado Banco Mundial - BM4. Este que assinala duas organizações: o Banco Internacional de Reconstrução e Desenvolvimento (Bird) e a Associação Internacional de Desenvolvimento (AID), que conformam, por sua vez, o Grupo Banco Mundial (GBM). Tal organismo é entendido como "[...] um conjunto de entidades cuja atuação em larga medida se articula e se concatena.” (PEREIRA, 2014, p. 20), o qual se destaca na propagação e controle do capitalismo pelo globo terrestre, em especial nos países da América Latina. “Isto porque o BM é um ator político, intelectual e financeiro, devido à sua condição absolutamente singular de emprestador, formulador e articulador de políticas [...]" (PEREIRA, 2014, p. 20), especificamente, no que se refere às áreas da agricultura e da educação.

Para Pronko (2014, p. 90), é notório a influência do BM nas políticas de educação, não somente do Brasil, mas de todos os demais países da América Latina e Caribe. "Essa perspectiva é fundamental para superar o duplo equívoco de pensar a atuação do BM como uma intervenção de fora para dentro (portanto, uma sobredeterminação do âmbito internacional sobre o nacional) e como uma imposição unilateral da qual 
os governantes locais seriam vítimas". Na realidade, os governos e o BM constroem parcerias, nas quais se aplicam as definições e orientações do órgão.

No campo da educação a atuação do BM se ampliará, a partir dos anos de 1990, tanto na elaboração e no financiamento quanto no controle das políticas educacionais. Estas que estarão delineadas diretamente pelos interesses das agências dos países centrais do capitalismo, as quais são propagadas como multilaterais, a exemplo do BM. (SOUZA, 2014).

Assim, a presença dos organismos internacionais, em especial o BM,

têm orientado as políticas educacionais nos países periféricos com o objetivo de responder, dentro dos limites do campo educacional e de sua possibilidade de alcance, à crise estrutural do capitalismo desencadeada nos anos de 1970, uma vez que a educação passou a ser vista não somente como uma importante fronteira econômica a ser explorada, mas também por sua funcionalidade aos grandes capitalistas em formar uma nova geração de trabalhadores que pudessem se adequar, em termos de conhecimentos e técnicas, às novas exigências produtivas e organizacionais de um contexto marcado pela reestruturação dos processos produtivos (crise do fordismo e advento do toyotismo) e por uma forte crise no Estado capitalista (MOTA JUNIOR; MAUÉS, 2014, p. 1139).

A educação passa a ser encarada como um elemento integrante do processo de expansão capitalista, sobretudo no campo, cujo discurso oficial cunhou o termo de "modernização agrícola". Nesse sentido, o processo educacional necessitava ser redimensionado, universalizado e ajustado para atender a formação de uma base de "capital humano" necessária aos projetos de expansão das fronteiras agrícolas e industriais dos países atendidos pelo BM. Nessa perspectiva,

seguindo os princípios da teoria do capital humano, a educação é considerada, principalmente, um investimento fundamental, socialmente produtivo e chave para o crescimento econômico, o desenvolvimento social e a redução da pobreza, metas que o banco afirma pretender alcançar (VIOR; CERRUTI, 2014, p.116).

No Brasil, o ideário norte-americano impôs a teoria do Capital Humano ${ }^{5}$, desde a década de 1960, incorporada à educação, nas reformas de ensino realizadas pelos militares, para adequar a educação aos interesses econômico-sociais que acompanhavam, desde aquele momento, a modernização agrícola e industrial do país. A tese da teoria de formação de Capital Humano resulta da demanda de exploração da força de trabalho pelo capitalismo, em sua fase imperialista, minimamente qualificada, para atender às novas técnicas e demandas do sistema produtivo (em seus constantes processos de restruturação).

Segundo Frigotto (2006, p.120), a teoria do capital humano constitui uma característica das teorias do desenvolvimento e das teses neocapitalistas, tratando-se, na realidade, de "uma especificidade das apologias do capitalismo em sua etapa monopolista [...].” A referida teoria foi construída nos Estados Unidos da América - EUA, na década de 1950, tendo Theodoro Schultz como ideólogo pioneiro. Daí nenhuma coincidência o fato de ter sido desenvolvida num país cuja forma monopolista do capitalismo se encontrava em sua fase imperialista. Nessa perspectiva, "a educação, então, é o principal capital humano enquanto é concebida como produtora de capacidade de trabalho, potenciadora do fator trabalho. Neste sentido é um investimento como qualquer outro." (FRIGOTTO, 2006, p. 40).

Dentro do processo educativo, a prática pedagógica passa a ser orientada, controlada e avaliada na capacidade de produzir um conjunto de habilidades intelectuais, definição de certas atitudes, transferência 
de um dado conjunto de conhecimentos que proporcionem a ampliação da capacidade de trabalho e, tão logo, de produção. Significa uma transmutação do conceito de bomo economicus para a prática pedagógica, a gerar um produto ao modo de produção capitalista: um homem com maior capacidade produtiva. Não interessa o homem enquanto homem, sujeito histórico, mas como representação de um conjunto de competências a serem desenvolvidas pela educação para se integrar ao sistema econômico-capitalista. De tal maneira, "se todos os indivíduos são livres, se todos no mercado de trocas podem vender e comprar o que querem, o problema da desigualdade é culpa do indivíduo", (FRIGOTTO, 2006, p. 61) que não se qualificou para tal, e não do capitalismo enquanto sistema econômico.

No contexto da crise do capitalismo, surgida desde a década de 1970, as diversas agências do sistema se reorganizaram por meio do sistema ideológico, político e de reprodução do capital na sociedade. Marca-se, então, o advento do chamado "neoliberalismo", por meio da redução do Estado no controle direto da economia e a adoção de um padrão de acumulação "flexível", mediante o modelo de produção toyotista (modelo racional e gerencial de recursos), em substituição ao fordismo (produção em larga escala e consumo em massa). (SAVIANI, 2007; SOUZA, 2014).

No referido contexto, realizou-se em Washington, ainda em 1989, um encontro "com o objetivo de discutir as reformas consideradas necessárias para a América Latina” (SAVIANI, 2007, p. 425), chamadas depois de "Consenso de Washington" (1989 e 1990). Esse encontro indicou uma série de recomendações a serem acatadas pelos países latino-americanos, dentre elas, “[...] um programa de rigoroso equilíbrio fiscal a ser conseguido por meio de reformas administrativas, trabalhistas e previdenciárias tendo como vetor um corte profundo nos gastos públicos." (SAVIANI, 2007, p. 426), operando, também, "uma rígida política monetária visando à estabilização" e [...] "a desregulação dos mercados tanto financeiros como do trabalho, privatização radical e abertura comercial.” (SAVIANI, 2007, p. 426).

Observa-se que tais políticas seriam impostas através de certas condições e pressões, no entanto, logo "perdem o caráter de imposição, pois são assumidas pelas próprias elites econômicas e políticas dos países latino-americanos." (SAVIANI, 2007, p. 426). No Brasil, como veremos adiante, tais medidas ganharam forma no Governo de Fernando Henrique Cardoso - FHC e se intensificam com Luís Inácio Lula da Silva (o Lula).

O capitalismo cria estratégias, no mesmo passo em que desenvolve as suas "teorias educacionais", para ajustar a educação aos seus interesses. De tal modo, em março de 1990, realizou-se a Conferência Mundial sobre Educação para Todos, organizada por diversos organismos internacionais: Fundo das Nações Unidas para a Infância (UNICEF), o Programa das Nações Unidas para o Desenvolvimento (PNUD), a Organização das Nações Unidas para a Educação, a Ciência e a Cultura (UNESCO) e o BM. Dessa conferência, são resultantes vários documentos ${ }^{6}$ com diversas "definições educacionais", as quais deveriam ser seguidas, sobretudo, pelos países subdesenvolvidos em suas reformas educacionais.

O estado brasileiro era governado, nesse período da década de 1990, por FHC (1995-2002). Tão logo, as diretrizes do neoliberalismo e de suas agências, especialmente do BM, foram assumidas pelo governo. 
O alinhamento estratégico entre o Ministério da Educação do Brasil (MEC) e o Banco Mundial era tamanho, nesse período, que os principais quadros responsáveis pelo governo brasileiro em matéria de educação, a começar pelo ministro, já haviam feito parte do staff como diretores ou como consultores das agências que compõem o Grupo Banco

Mundial e outras agências multilaterais (MAUÉS; MOTA JÚNIOR, 2014, p. 1139).

Tal alinhamento se comprova, para além das demais evidências, ao se perceber o interesse do BM com as políticas de educação no Brasil a partir de suas próprias publicações. Dos documentos-base, resultantes das medidas neoliberais impostas ao Brasil, destacamos o texto "Atingindo uma educação de nível mundial no Brasil: Próximos Passos”, publicado em 2010 pelo BM. Este é um documento de suma importância, não só por elucidar a relação BM e governos brasileiros, mas por demonstrar a origem, os significados e o objetivo das políticas educacionais brasileiras: atingir resultados.

\section{A avaliação do Banco Mundial sobre as políticas neoliberais de educação nos governos de FHC e $\boldsymbol{L} \boldsymbol{U L A}$}

O documento em questão, acima referido, possui como objetivos: 1) descrever um balanço das mudanças processadas pelas reformas educacionais, definidas e orientadas pelo órgão, na educação brasileira no período que compreende os dois mandatos de Fernando Henrique Cardoso (FHC) e Luís Inácio Lula da Silva (1995 a 2010); e, 2) seguir orientando os rumos das políticas educacionais no país no sentido de manter e aprofundar a hegemonia de seu modelo de educação.

Para o BM, o sistema educacional dos países periféricos deve exercer três papéis, considerados centrais, quais sejam: 1) o incremento de "habilidades da força de trabalho para sustentar o crescimento econômico"; 2) suporte à "redução da pobreza e desigualdade", proporcionando equidade, "educação para todos"; 3) o sistema educacional voltado para "transformar gastos na educação em resultados educacionais" (BANCO MUNDIAL, 2010, p.2). Esse último aspecto ganha notória importância, tendo em vista uma concepção de educação gerencial, pautada no racionamento de recursos e voltada, sobretudo, aos resultados.

A concepção de educação, entendida pelo BM para os países como o Brasil, é voltada exclusivamente para os resultados, pautada em capacitação e treinamento técnico das massas pobres para inserção no "mundo do trabalho", ou seja, ativar as capacidades produtivas e a "promoção do uso produtivo do trabalho", por meio das competências e habilidades adquiridas no processo educativo (capital humano). Assim, preconiza-se uma forma específica de educação para a redução da pobreza, "ao aumentar a produtividade dos pobres”. (BANCO MUNDIAL, 1996, p.1).

De tal maneira, a avaliação do Banco Mundial (2010), sobre a educação brasileira, resultante dos investimentos financeiros desse organismo para o gerenciamento de reformas educacionais (criação de políticas e programas) no Estado brasileiro em um período de quinze anos (1995-2010), se mostra extremamente positiva. Para isso, o banco utiliza de comparações feitas entre às estatísticas educacionais sobre a crescente do número médio de anos de estudos da população brasileira, em especial no que tange aos mais pobres. Dessa feita, considera satisfatório o aumento da escolaridade da força de trabalho, assim 
como o nível de formação dos professores e os resultados dos estudantes brasileiros no Programme for International Student Assesstment (PISA). (BANCO MUNDIAL, 2010).

Segundo a avaliação do Banco Mundial (2010), as reformas educacionais brasileiras, iniciadas desde o ano de 1995 com FHC, representaram uma "revolução" na gestão da educação brasileira, principalmente, pelos seguintes fatores: a) a distribuição equilibrada do financiamento educacional em todas as regiões, Estados e Municípios brasileiros, a partir da implantação do FUNDEF; b) a verificação do aprendizado por meio da criação de um sistema nacional comum de avaliação (Sistema de Avaliação da Educação Básica - SAEB); c) a criação de um programa de "incentivo" ao acesso educacional para os pobres (Bolsa Escola).

Conforme o BM, no governo de FHC (1995-2002), “com estas reformas, mais a Lei de Diretrizes e Bases da Educação Nacional (1996) e as primeiras diretrizes nacionais de currículo, o Ministério da Educação alinhou os elementos centrais de uma política de educação nacional." (BANCO MUNDIAL, 2010, p. 1).

Continuando aos "elogios" e considerações aos dois governos brasileiros (FHC e Lula), o Banco Mundial afirma quanto ao governo de Lula (2003-2010):

A administração do governo Lula, iniciada em 2002, não só manteve estas políticas centrais, como também as ampliou e fortaleceu. A equalização de financiamento do FUNDEF foi estendida ao ensino médio e à pré-escola e foi re-batizado de FUNDEB. A Bolsa Escola foi consolidada com outros programas de transferência de renda e virou o Bolsa Família [...]. (BANCO MUNDIAL, 2010, p.1).

A apropriação e continuidade por Lula dos programas de FHC é algo que o Banco faz questão de ressaltar, sobretudo, pelo aperfeiçoamento e aplicação de tais programas conforme as diretrizes do próprio BM: o discurso de "combate à pobreza" e o impulso na formação de capacitação para o trabalho (capital humano) para atender as novas demandas.

O Banco Mundial (2010) ressalta ainda a maior colaboração do governo Lula com suas diretrizes, em relação à FHC, sobretudo, pela ampliação dos testes padronizados de avaliação e mensuração da educação (resultados), como a transformação do SAEB de uma amostra nacional pequena e localizada de estudantes para o âmbito nacional (matemática e português), chamado agora de "Prova Brasil" e aplicada a todos os estudantes de ensino fundamental II ( $4^{a}$ a $8^{a}$ séries). O Banco é mais elogioso ainda quando se refere à criação de um índice nacional da educação básica: "combinando dados sobre o fluxo escolar e as médias nos testes padronizados (Prova Brasil/SAEB), O MEC/INEP desenvolveu um índice de desempenho escolar chamado IDEB (Índice de Desenvolvimento da Educação Básica)." (BANCO MUNDIAL, 2010, p.2).

Ainda no ensaio considerativo, de satisfação do seu alinhamento ao governo Lula, o Banco Mundial (2010), ao descrever as mudanças processadas com as políticas implementadas pelo Estado brasileiro, aponta o apoio recebido do governo para os seus investimentos educacionais no Brasil. Investimentos esses materializados em programas e políticas, em todo o território nacional, tais como: Programa Mais Educação, expansão do ensino técnico profissional, os programas do FUNDESCOLA, etc. 
O apoio a investimentos inclui programas tais como o Mais Educação e a expansão das escolas técnicas federais. O governo federal também tem apoiado firmemente a inovação - seja o planejamento em nível de escola com o FUNDESCOLA, o ensino multiseriado da Escola Ativa, ou o apoio ao planejamento estratégico das administrações estaduais e municipais de educação com o PAR . (BANCO MUNDIAL, 2010, p.2).

Observa-se, portanto, que o balanço do Banco Mundial para com os seus objetivos na educação brasileira foi de extrema satisfação, sobretudo, pela abertura dada pelos governos (FHC e muito mais Lula) para a inversão de suas definições em matéria de educação, assim como, de exercício do controle de seus resultados (a partir dos instrumentos de avaliação criados, SAEB, IDEB, Prova Brasil, etc.).

Nas prerrogativas do BM, se materializavam as políticas e programas do imperialismo capitalista como estratégias de dominação ideológica, restruturação produtiva, e maiores exigências na exploração da força de trabalho (nível básico de educação, com aquisição de competências e habilidades específicas).

O segundo eixo do documento do Banco Mundial (2010) em questão, propõe seguir orientando os rumos das políticas educacionais no país, na influência, definição e controle da educação. Para o BM, os "próximos passos” das políticas de educação no Brasil devem ser de:

1) manter o rumo atual das políticas centrais dos últimos 15 anos (a equalização de financiamento do FUNDEB, a mensuração de resultados do IDEB, e as transferências condicionais de renda do Bolsa Família).

2) se concentrar na eficiência de gastos ao invés de metas para gastos mais altos, o que pode piorar os riscos de perda da qualidade do gasto e a corrupção no sistema.

3) criar incentivos de mais recursos para os estados que integrem os sistemas escolares estaduais e municipais e menos incentivo federal direto para pequenos sistemas escolares municipais.

4) aproveitar o 'laboratório de ação educacional' brasileiro através de avaliações de impacto de programas inovadores e promoção de políticas e práticas com base em evidência. (BANCO MUNDIAL, 2010, p. 8).

Podemos inferir, de tais pressupostos, que o BM está orientando aos governos brasileiros a continuarem e aprofundarem a lógica neoliberal à educação. De tal maneira, o mesmo defende a educação para os resultados, cuja o treinamento e as características do tecnicismo ganham forma. Nisso, o objetivo das práticas educativas não é de que o aluno aprenda, mas que atinja bons índices nos testes padronizados a ele aplicados.

Seguidamente, se observa a preconização pela redução dos gastos públicos em educação, reduzindo-se os problemas educacionais do país a uma suposta ineficiência dos gastos. No entanto, o que se observa, na prática, é a precarização e sucateamento dos sistemas de ensino público (básico e superior) com escolas e universidades afetadas em seu funcionamento, justamente devido aos cortes de verbas e despesas pelo atual governo e governos recentes.

Tais presunções revelavam a perspectiva neoliberal protegida pelo Banco em relação ao papel mínimo do Estado na economia, tão logo também na educação. No Brasil, como apontamos, essa percepção de educação dos organismos internacionais vem sendo divulgada e defendida, desde a década de 1990, por meio da Reforma do Estado e mediante medidas complementares que garantam os objetivos de tais reformas. Estas medidas vêm sendo tomadas, no Brasil, por meio da nova Base Nacional Comum Curricular - BNCC e da reforma do Ensino Médio, as quais se aliam à Emenda Constitucional de redução de gastos 
públicos e, até mesmo, à reforma trabalhista que está em curso. No entanto, tais medidas não são objeto deste estudo.

Por fim, no tópico que se segue, demonstraremos a assertiva neoliberal do BM à educação brasileira, na redução, na privatização e no controle das políticas de educação. Para tanto, analisaremos, mesmo que brevemente, as mais recentes definições e orientações do BM à educação brasileira, dentro do pacote de ajustes e reduções preconizadas pelo ideário neoliberal.

\section{A definição e imposição de um ajuste injusto à Educação Brasileira}

Em novembro de 2017 o BM publicou o texto intitulado "Um Ajuste Justo - Análise da Eficiência e Equidade do Gasto Público no Brasil", o qual objetiva definir as suas novas medidas e reformas neoliberais à sociedade brasileira, as quais compete aos governos (o atual e os futuros) implementar. Segundo consta no Prefácio do "Volume I- Sintese":

Após um período de estabilidade econômica, altas taxas de crescimento e redução substancial da pobreza, o Brasil enfrenta hoje grandes desafios para lidar com seus gastos públicos. O crescimento das despesas primárias superou o PIB mesmo durante a fase favorável do super ciclo das commodities. O gasto tornou-se cada vez mais engessado pela rigidez constitucional em categorias como folha de pagamento e previdência social, deixando quase nenhum espaço para despesas discricionárias e de investimento.

$[\cdots]$

Atento à mudança de cenário, o governo federal solicitou ao Banco Mundial a elaboração deste relatório, com o objetivo de realizar uma análise aprofundada dos gastos do governo, identificar alternativas para reduzir o déficit fiscal a um nível sustentável e, ao mesmo tempo, consolidar os ganhos sociais alcançados nas décadas anteriores. (BANCO MUNDIAL, 2017, p. 1, grifo nosso).

Como evidenciado pelo documento, o estudo foi solicitado pelo governo brasileiro, tendo em vista que o BM é a principal agência formuladora dos programas e recursos que balizam a educação nacional, seja no âmbito da educação básica ou superior. Nessa acepção, o BM alega que os gastos primários do país (dentre eles estão os de educação) estão altos a ponto de superarem a arrecadação do PIB, sendo necessário que a "rigidez" constitucional seja quebrada para se fazer desonerações de gastos, a exemplo da redução em folhas de pagamento e a criação de mecanismos previdenciários mais duros, no acesso dos trabalhadores à benefícios previdenciários, sobretudo, o de aposentadoria.

O estudo é baseado em comparativos internacionais, especialmente aos países que compõem a Organização para a Cooperação e Desenvolvimento Econômico - OCDE, assim como na revisão da eficácia dos gastos entre as diferentes entidades e programas governamentais. O esboço é abrangente e trata de questões como das políticas industriais para o setor automotivo, políticas de apoio ao empresariado, sustentabilidade fiscal, peso da folha de funcionalismo público, estratégias de eficiência fiscal, previdência social, mercado de trabalho e assistência social, assim como serviços de saúde. O último tópico do documento aborda os gastos em educação, intitulado de "Gastar Mais ou Melhor? Eficiência e Equidade da Educação Pública". Desta forma, nos deteremos em análise ao mesmo, por se referir, especificamente, às políticas educacionais do Estado brasileiro. 
De tal maneira, traremos à tona alguns dos pontos, enumerados no referido documento, referentes à educação básica (Ensino fundamental e médio), dando a este nível de educacional, o recorte deste trabalho às políticas educacionais aqui abordadas.

No tocante ao Ensino fundamental e médio, segundo o BM,

o Brasil obteve melhoras significativas na prova de matemática do PISA (Programa Internacional de Avaliação de Estudantes). A nota média brasileira passou de $68 \%$ para $79 \%$ da média da OCDE entre 2002 e 2012. Contudo, desde então, os resultados caíram para 77\% em 2015 (o mesmo nível de 2009). Quando se controla pelo nível de gasto por aluno, os resultados do PISA ainda são decepcionantes. (BANCO MUNDIAL, 2017, p. 124).

O argumento apresentado pelo BM é o de que o Brasil gasta muito mais em educação do que os Países que integram a OCDE, sendo que os resultados, por outro lado, são muito inferiores. Nesse argumento, o organismo detectou que, no ano de 2014 , '[...] as despesas com educação chegaram a $6 \%$ do PIB. Já em 2010, os gastos com educação no Brasil eram superiores à média dos países da OCDE (5,5\%), do BRICS (5,1\%) e da América Latina (4,6\%).” (BANCO MUNDIAL, 2017, p. 123).

No argumento acima, torna-se claro a insatisfação do BM em relação aos gastos educacionais do Brasil, ressaltando que o país deveria despender menos recursos do seu Produto Interno Bruto - PIB à educação básica. Para o Banco, o país deveria gastar em educação algo proporcional ao que gastam os países da OCDE. No entanto, o BM não atenta aos diversos fatores internos do país, históricos, sociais, econômicos, geográficos e demográficos que, justamente, diferencia o Brasil dos países da OCDE. Um país que conseguiu universalizar o acesso à educação básica, por exemplo, apenas na virada do século XX para o XXI. A escola foi, historicamente, uma instituição da elite dominante e por isso, um espaço de poucos privilegiados. Os gastos com educação, no período referido pelo BM (2002 - 2014) referem-se, em grande parte, às políticas de promoção do acesso de grande parte dos sujeitos à escola.

Em seguida, segundo o BM (2017), o baixo desempenho do sistema educacional brasileiro está refletido pelas altas taxas de reprovação e de evasão escolar. Nessas duas questões, detectou-se que "mais de $35 \%$ dos alunos repetiram pelo menos um ano no ensino fundamental e médio [...]. As taxas de evasão escolar também são altíssimas (26\%) em comparação com a OCDE (4\%) e países comparáveis da região (14\%)". (BANCO MUNDIAL, 2017, p. 125). Ainda para o Banco, a reprovação e evasão “[...] resultam em um percentual surpreendentemente alto de alunos que não concluem o ensino médio antes dos 25 anos de idade”. (BANCO MUNDIAL, 2017, p. 126). Para o organismo, essas são evidências do que chama de "ineficiência" das políticas de gestão educacional, as quais discutiremos a seguir.

Com relação às políticas de gestão, o BM considera que a baixa qualidade dos professores brasileiros é o principal fator que restringe a qualidade da educação. Enfatiza que a formação inicial do magistério é precária e de baixo requisito, o que se alia à diminuta seletividade e falta de instrumentos que mensurem o desempenho docente.

O magistério permanece uma profissão desprestigiada. Os requisitos para ingresso em cursos de licenciatura são fracos e a formação é de baixa qualidade. É além da pouca seletividade na contratação de professores para os sistemas educacionais estaduais e municipais, os salários não são vinculados do desempenho. A mudança desse paradigma 
exigirá reformas coordenadas de políticas públicas nas esferas federal, estadual e municipal (BANCO MUNDIAL, 2017, p. 127).

O que o Banco propõe, ao sistema brasileiro, em essência, é a criação de mecanismos mais rígidos de seletividade dos professores, desde o ingresso aos cursos de licenciaturas até a processos seletivos de contratação dos mesmos. No entanto, o que se apresenta mais preocupante, nas orientações do BM, é a indicação de que os professores sejam avaliados constantemente, a partir dos seus resultados e, por meio disso, a possível demissão daqueles com desempenho inferior às taxas e índices previstos. Na realidade, se trata de uma visão gerencial, uma transmutação da lógica privada, empresarial e serial para o setor público, na qual alunos e professores, longe de serem considerados sujeitos, são considerados produtos, mercadorias cujo processo se condiciona por uma lógica produtiva e de resultados quantificados.

Além de colocar a "baixa qualidade" dos professores como responsável principal pela ineficiência da educação, o BM (2017, p. 129) recomenda que “[...] o Brasil poderia aumentar o número de estudantes por professor em 33\% no ensino fundamental e em 41\% no ensino médio". Esta medida seria em função da média nacional aluno professor ser, em 2014, de 23 alunos no ensino Fundamental I, e 19 no ensino Fundamental II.

O BM desconsidera, no entanto, as fragmentações territoriais do Brasil, onde há regiões de baixa intensidade demográfica, como no Norte e Nordeste, cuja população em idade escolar é menor, sobretudo nas zonas rurais, em comparação as demais regiões. Nas metrópoles e grandes cidades, dificilmente se encontrará uma única escola com turmas abaixo de 20 alunos. Ao contrário, as turmas são numerosas, às vezes, chegando a mais de 40 alunos.

Quanto à valorização dos professores, o BM pondera que o piso nacional está em acordo aos padrões internacionais, se feita a comparação do Brasil aos demais países similares. No entanto, critica as rápidas "promoções" adquiridas pelos docentes ao longo de suas carreiras, assim como os supostos "benefícios" em planos previdenciários.

Devido às promoções automáticas baseadas nos anos de serviço e da participação em programas de formação, em 15 anos de carreira os salários se tornam duas a três vezes superiores ao salário inicial, em termos reais. Essa evolução supera significativamente a maioria dos países no mundo. Além disso, vale destacar que os professores brasileiros têm direito a planos previdenciários relativamente generosos quando comparado a outros países da OCDE (ver o capítulo sobre a previdência). (BANCO MUNDIAL, 2017, p. 127).

O banco define, contudo, que para os professores deve ser tomada medidas, tais como: 1) reduzir o número de professores, a partir do aumento da relação aluno-professor; 2) reduzir o absenteísmo entre os professores, "causadas por leis permissivas que concedem licenças por muitos motivos não verificáveis." (BANCO MUNDIAL, 2017, p. 130); 3) criação de instrumentos que balizem relação entre o desempenho, a estabilidade e a remuneração, inclusive “introdução e aplicação de ameaças de demissão por absenteísmo excessivo". (BANCO MUNDIAL, 2017, p. 130); 4) limitar o ingresso de professores efetivos por meio de concurso público, isso porque a "[...] demissão é extremamente difícil e cujos custos são significativos, uma vez que eles se aposentam cedo com vencimentos integrais"; e, 5) aumentar a tributação da renda previdenciária atual para os professores. 
Estas são medidas pleiteadas na esteira do neoliberalismo, a partir das políticas de Estado mínimo, precarização e privatização dos serviços públicos. Faz-se assim, mediante o desmoronamento da soberania nacional e em matéria de política econômica, a destruição de todo e qualquer gasto social e trabalhista que onere a rentabilidade dos capitalistas. De tal maneira, conforme Pronko (2014, p. 98), “[...] o BM afirma que não é preciso que o Estado seja o único provedor de serviços básicos, abrindo as portas para provedores privados competitivos em atividades até agora reservadas ao setor público". Ainda segundo a autora, "a reforma do Estado, definida no documento em suas orientações estratégicas, passa a ser a única saída das nações para se adequarem às novas condições mundiais. (PRONKO, 2014, p. 98).

$\mathrm{O}$ ajuste recomendado pelo BM perpassa, sobretudo, pela privatização dos setores educacionais e seus conseguintes serviços, o que já vem ocorrendo a passos largos na educação brasileira. Isso se comprova, concretamente, nas últimas recomendações do Banco postas no documento em questão.

A contratação de empresas privadas para o fornecimento de serviços de educação também poderia melhorar o desempenho e a eficiência dos gastos públicos com educação. [...]. Por poderem ser penalizadas por mau desempenho, elas baseariam as decisões sobre contratação, demissão, promoções e salários no desempenho individual dos professores, e não em sua estabilidade ou antiguidade (BANCO MUNDIAL, 2017, p. 127).

Portanto, as orientações e definições do BM podem e devem ser compreendidas, nada mais, como um conjunto de imposições, as quais passam a ser assumidas, defendidas e aplicadas pelos governos federal e estaduais, a partir das diversas reformas em curso no âmbito da educação.

Devemos tomar como exemplo máximo da privatização, a chamada "Nova Política de Formação de Professores”. Esta política cria novos mecanismos de transferências, por meio do PROUNI, de verbas públicas para instituições privadas; a retomada da Universidade Aberta do Brasil - UAB que possibilita uma formação aligeirada e precarizada de professores; impõe-se uma padronização curricular nos cursos de formação de professores (à espelho da BNCC na educação básica); e, reformulação nas políticas de estágio docência, a partir da "residência pedagógica" e reagrupamento do Programa Institucional de Bolsas de Iniciação à Docência - PIBID como ponte entre a BNCC na educação básica e os currículos dos cursos de formação inicial de professores.

\section{Resultados/conclusão}

A proposta deste trabalho residiu em elucidar, mesmo que parcialmente, as principais definições e orientações do Banco Mundial nas políticas de educação brasileiras. Tais definições pertencem, no seu conjunto, ao ajuste estrutural do capitalismo, iniciado desde a década de 1990, no chamado neoliberalismo. O BM indica a realização de investimentos privados na educação, ao passo de privatizá-la por completo. Para tal feito, o organismo vem criando uma rede de influência mútua nas informações sobre as conveniências de se investir em educação nos países receptores dos empréstimos, cuja economia neocolonial se faz presente, submetida aos interesses dos países de alto capital financeiro-monopolista. 
A educação passa a ser redimensionada e ajustada aos interesses do mercado. Entra em cena, novamente, o discurso de formação de capital humano, a partir de capacitação, treinamento e competências técnicas ao exercício do trabalho manual. Neste sentido, a própria formação dos educadores ganha, também, tal característica de instrução e treinamento, ao passo que possa haver competitividade entre os próprios sujeitos que desenvolvem a educação.

A formação de professores é proposta mais por meio de treinamento em método de instrução do que na formação teórico-prática. A recomendação do BM é tornar os salários docentes competitivos, com oferta de incentivos por desempenho na função, com consequente progressão profissional, desconsiderando, portanto, as diferenças de habilidades possivelmente existentes entre esses sujeitos.

Esse quadro de educação para as competências técnicas, capital humano, treinamento e capacitação se fortalecerá, como demonstrado, por meio das políticas educacionais criadas e gerenciadas nos governos de FHC e Lula (1995 - 2010), tendo por base a própria avaliação positiva que faz o BM sobre como ambos os governos aplicaram as reformas e mudanças "necessárias" na educação. Um processo educativo para os resultados foi pauta em ambos os governos e busca atender as pautas do mercado, cuja competitividade, intensificada pelo desemprego generalizado, possa facilitar as formas precárias de exploração do trabalho, os baixos salários e o pouco resguardo das Leis trabalhistas.

O ajuste considerado "justo" pelo BM coloca a educação na esteira, de fato, da precarização e da privatização, ao passo que retoma e impõe às práticas gerencias, assim como a prerrogativa de uma educação tecnicista, formação mínima rasante e superficial. Nessa perspectiva, renuncia-se a teoria e prática da educação escolar na formação integral, holística e totalizante do ser humano enquanto sujeito histórico.

O documento "Um Ajuste Justo - Análise da Eficiência e Equidade do Gasto Público no Brasil", no tocante à educação, realiza uma projeção para medidas mais arrojadas, diante as duas décadas de reformas educacionais neoliberais, traçando novas orientações para o atual governo realizar suas reformas (BNCC, Reforma do Ensino Médio, Novas Diretrizes de Formação de Professores, etc.). Finca-se no tripé: financiamento, avaliação sistêmica e gestão gerencial. Neste tripé, os resultados educacionais brasileiros são pautados de crescer nas avaliações internacionais (sobretudo, o PISA) e os números de escolarização cheguem ao patamar dos países da OCDE.

São preposições, portanto, de uma concepção burguesa de sociedade e de educação. Os valores empregados à educação são os de consolidação do Estado Neoliberal, quanto na formação de uma estrutura educativa baseada na Teoria do Capital Humano (instrução, treinamento, capacitação técnica, etc.), necessária à manutenção do status quo da geopolítica capitalista mundial.

\section{Referências}

BANCO MUNDIAL. Atingindo uma Educação de Nível Mundial no Brasil: próximos passos sumário executivo. 2010. Disponível em: <http://cenpec.org.br/biblioteca/educacao/estudos-epesquisas/achieving-world-class-education-in-brazil-the-next-agenda>. Acesso em: 10 abr. 2019.

BANCO MUNDIAL. Conferencia Mundial sobre Educación para Todos: Satisfacción de las Necesidades Básicas de Aprendizaje. Jomtien, Tailandia, marzo de 1990. 
BANCO MUNDIAL. Estrategia sectorial de educación: Grupo del Banco Mundial, Red sobre Desarrollo Humano. Washington, DC/Banco Mundial, 2000.

BANCO MUNDIAL. Prioridades y estrategias para la educación: examen del Banco Mundial. Washington: DC/Banco Mundial, 1996. (El desarrollo en la práctica). 218p.

BANCO MUNDIAL. Um Ajuste Justo: Análise da eficiência e da equidade do gasto público no

Brasil. Grupo Banco Mundial, 2017. Disponível em:

<https://www.worldbank.org/pt/country/brazil/publication/brazil-expenditure-review-report>. Acesso em: 05 mar. 2019.

FRIGOTTO, G. A produtividade da escola improdutiva: um (re)exame das relações entre educação e estrutura econômico-social e capitalista. 8. ed. São Paulo: Cortez, 2006.

MOTA JUNIOR, W. P.; MAUÉS, O. C. O Banco Mundial e as Políticas Educacionais Brasileiras. Educação \& Realidade, v. 39, n. 4, Out./Dez., 2014, pp. 1137-1152.

PEREIRA, J. M. M. Poder, política e dinheiro: a trajetória do Banco Mundial entre 1980 e 2013. In: PEREIRA, J. M. M.; PRONKO, M. (Org.). A demolição de direitos: um exame das políticas do Banco Mundial para a educação e a saúde (1980-2013). Rio de Janeiro: Escola Politécnica de Saúde Joaquim Venâncio, 2014. p.19-63.

PRONKO, M. O Banco Mundial no campo internacional da educação. In: PEREIRA, João Márcio Mendes Pereira; PRONKO, Marcela (Org.). A demolição de direitos: um exame das políticas do Banco Mundial para a educação e a saúde (1980-2013). Rio de Janeiro: Escola Politécnica de Saúde Joaquim Venâncio, 2014. p.89-112.

SAVIANI, D. História das idéias pedagógicas no Brasil. Campinas, SP: Autores Associados, 2007.

SOUZA, M. M. Imperialismo e educação do campo. Araraquara: Cultura Acadêmica, 2014.

VIOR, S.; CERRUTI; M. B. O. O Banco Mundial e a sua influência na definição de políticas educacionais na América Latina (1980-2012). In: PEREIRA, J. M. M. P.; PRONKO, M. (Org.). A demolição de direitos: um exame das políticas do Banco Mundial para a educação e a saúde (1980-2013). Rio de Janeiro: Escola Politécnica de Saúde Joaquim Venâncio, 2014. p. 113-151.

\footnotetext{
Notas:

1 Mestrado em Educação pelo Programa de Pós-Graduação em Formação de Professores e Práticas Interdisciplinares (PPGFPPI), Universidade de Pernambuco - UPE Campus Petrolina (2018.1). Graduado em História pela mesma instituição e Pedagogia pela Faculdade de Educação Superior de Pernambuco - FAESPE. Atualmente é Professor da Educação Básica, atuando como Coordenador Pedagógico do Município de Petrolina - PE. ORCID: https://orcid.org/0000-0002-4356-2914 E-mail: francielupe@gmail.com

2 Doutorado em Educação pela Universidade Federal do Ceará-UFC (2012, Mestrado em Sociologia pela Universidade Federal do Ceará-UFC (2001), Especializada em Afabetização pela Universidade Regional do Cariri-URCA (1997) e Licenciatura em História pela Universidade Regional do Cariri-URCA (1989). Atualmente é Professora-adjunta do Colegiado de Nutrição da Universidade de Pernambuco-UPE, Campus Petrolina. Atua como professora permanente do Programa de Pós-graduação em Formação de Professores e Práticas Interdisciplinas -PPGFPPI, da Universidade de Pernambuco-UPE. ORCID: https://orcid.org/0000-0001-56551184E-mail: maria.leite@upe.br

3 Os EUA se apresenta como principal país nas relações ao Brasil, tanto na esfera econômica quanto política. Sobre isso, ver o documentário "O dia que durou 21 anos" (https://www.youtube.com/watch?v $\left.=_{\mathrm{v}-H h h d g Y O a A}\right)$. No entanto, tal influência transgrediu aos aspectos sociais (as expressões da língua, costumes, modismos, etc.).

${ }^{4}$ Utilizamos a partir daqui a sigla "BM" toda vez que nos referimos ao Banco Mundial.

5 Teoria construída nos Estados Unidos da América - EUA, na década de 1950, tendo Theodoro Schultz como ideólogo pioneiro.

${ }^{6}$ Dentre eles destacam-se: a Declaração Mundial de Educação para Todos (1990); Prioridades y estratégias para la educación exame del Banco Mundial (1996); Atingindo uma educação de nivel mundial no Brasil: Próximos Passos (2010); Aprendizagem para Todos Investir nos Conhecimentos e Competências das Pessoas para Promover o Desenvolvimento - Estratégia 2020 para a Educação do Grupo Banco Mundial (2011), dentre outros.
} 